\title{
20.
}

Journal of Rehabilitation Research

and Development Vol. 28 No. 2, 1991

Pages 79-90

CLINICAL REPORT

\section{Report on the Evaluation of the VA/SEATTLE Ankle}

\author{
Prepared by the Rehabilitation R\&D Evaluation Unit, Rehabilitation Research and Development Service, \\ Department of Veterans Affairs, Baltimore, MD 21202
}

\begin{abstract}
The VA/SEATTLE Ankle was researched and developed by the Prosthetics Research Study (PRS), Seattle, WA under the sponsorship of the Rehabilitation Research and Development Service, Department of Veterans Affairs. This report presents an evaluation of the project conducted by the Rehabilitation R\&D Evaluation Unit (REU), the VA Prosthetic and Sensory Aids Service (PSAS), and the PSAS at 13 VA Medical Centers. The ankle is a lightweight lower limb prosthesis of monolithic design weighting $300 \mathrm{~g}(10.5 \mathrm{oz}$.) with a maximum pylon length of 15 $1 / 2$ in. Energy storage and release and three-axis motion are all accomplished via a specifically designed convolution in the distal region (ankle) of the pylon. This convolution provides rotation ( \pm 5 degrees), inversion/eversion ( \pm 3 degrees) and dorsi/plantar flexion ( \pm 5 degrees). The ankle showed no signs of fracture or wear through laboratory test procedures of 500,000 cycles of the ankle attached to a conventional type SACH foot under a dynamic load. Performance of the VA/SEATTLE Ankle was found to be acceptable and reliable with a wide variety of users and its commercial production was recommended.
\end{abstract}

Key words: amputee gait analysis, lightweight limb prostheses, pylon, SACH Foot, VA/SEATTLE Foot.

\section{INTRODUCTION}

Attempts to improve amputee gait to approach normal physiological walking motion of the torso and lower limbs has been a challenge confronted by physicians, prosthetists, engineers, and therapists. The SEATTLE Ankle is one

For further information, contact: Saleem J. Sheredos, acting director, Rehabilitation R\&D Evaluation Unit, VA-PRDC, 103 S. Gay St., Baltimore, MD 21202. Phone: 301-962-2133. component in the development of a complete functional, lightweight lower limb prosthesis. It replaces the pylon used in conventional endoskeletal limbs and incorporates limited degrees of plantar/dorsiflexion, inversion/eversion and axial rotation.

Subjects included in the evaluation represented a broad range in age, weight, and activity level. The subjects were asked to rate their performance of certain activities while wearing the SEATTLE Ankle as compared to the prosthesis they previously used. Subjects noted improved performance in the ambulatory functions of walking either slow or fast, running, going up or down stairs, going up or down hills, and going over uneven terrain. The group of subjects with the highest activity level showed the greatest improvement rating. Ninety-eight percent of the subjects said that the ankle movement was smooth during all phases of gait. The ankle functioning was essentially noiseless and only three subjects reported functional failures during the evaluation period.

\section{REVIEW OF DEVELOPMENT}

The SEATTLE Rotator Shank evolved into a lightweight multi-axis ankle of monolithic construction and is now known as the SEATTLE Ankle. First generation prototypes were built of graphite fabric layed up wet in a semirigid polyurethane matrix, with the bias at 45 degrees in flexing regions and omni-directional in stiff regions. Squeeze molds made of epoxy from hard mand rels compressed the layup to a 70 percent fiber 30 percent resin ration by weight. This material has great potential in other 


\section{FIGURE 1}

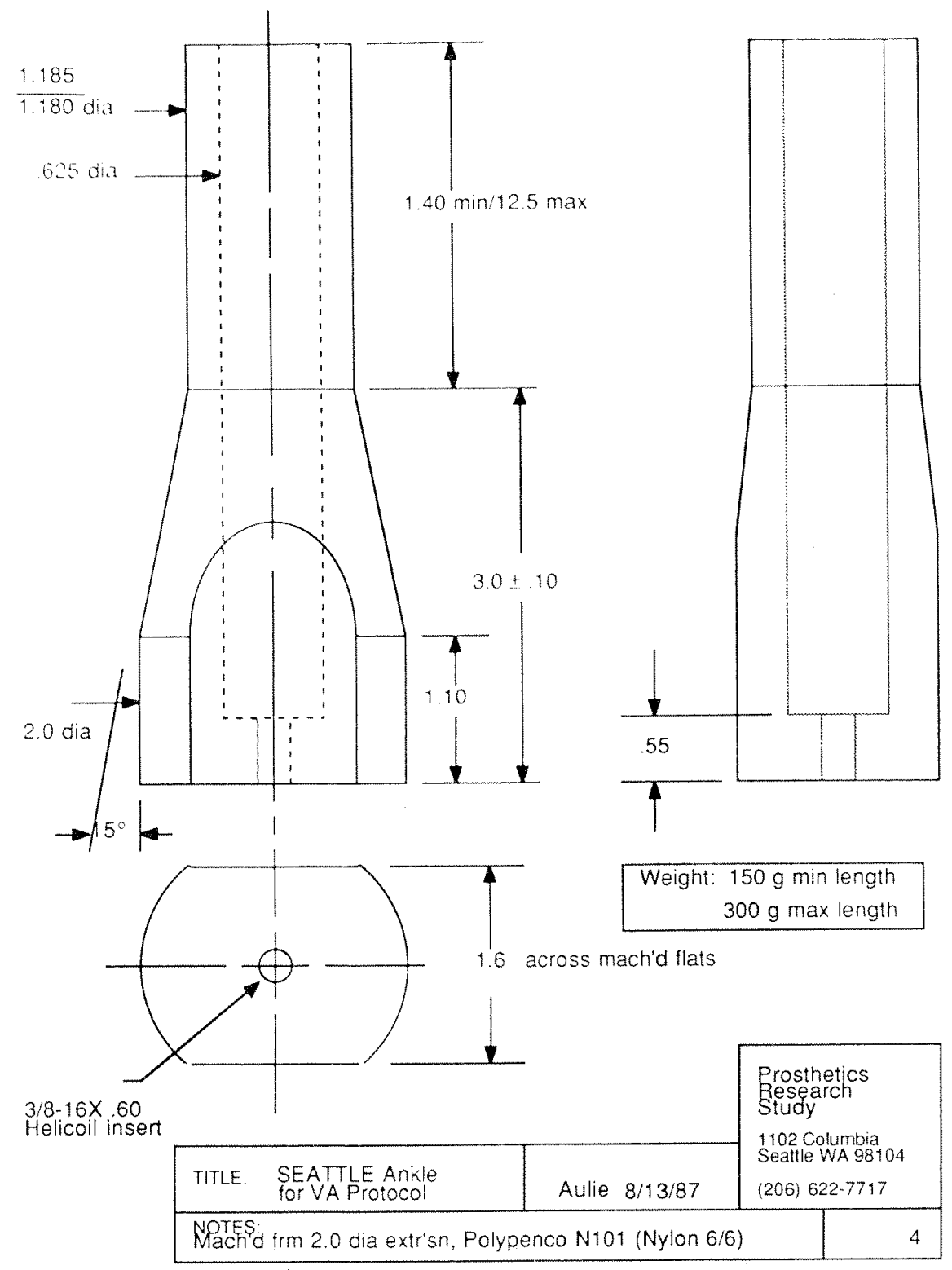

Figure 1.

SEATTLE Ankle for VA protocol.

prosthetic-orthotic applications.

A series of design iterations driven by clinical requirements resulted in a monolithic design with stress levels low enough for application of engineering thermoplastics. The current units are turned by conventional machining methods from 2 in. diameter extruded bars of nylon 6/6. Total manufacturing cost has been reduced drastically and part count reduced to two: the ankle body and a threaded insert for a standard 3/8-16 foot bolt.

Good results of PRS in-house clinical testing were the prime mover in the development of this device, as was the potential for low cost to the end user. Other design constraints included: weight, packaging (e.g., size constraints), corrosion resistance, and loading to $2.5 \times$ a $200 \mathrm{lb}$. body weight.

At PRS, heavy use testing by eight below-knee and two above-knee amputee subjects resulted in no failures over time periods of up to 16 weeks. Several subjects requested to be returned to the ankle following the test protocol and were fitted for long-term use. Gait laboratory analysis was done throughout the design process to protect against possible deleterious effects of the new ankle device on gait patterns and the residual limb.

Patent protection of the "entrapment" design was requested. Many standard machine elements were eliminated in the SEATTLE Ankle, such as pivot pins, bearing 


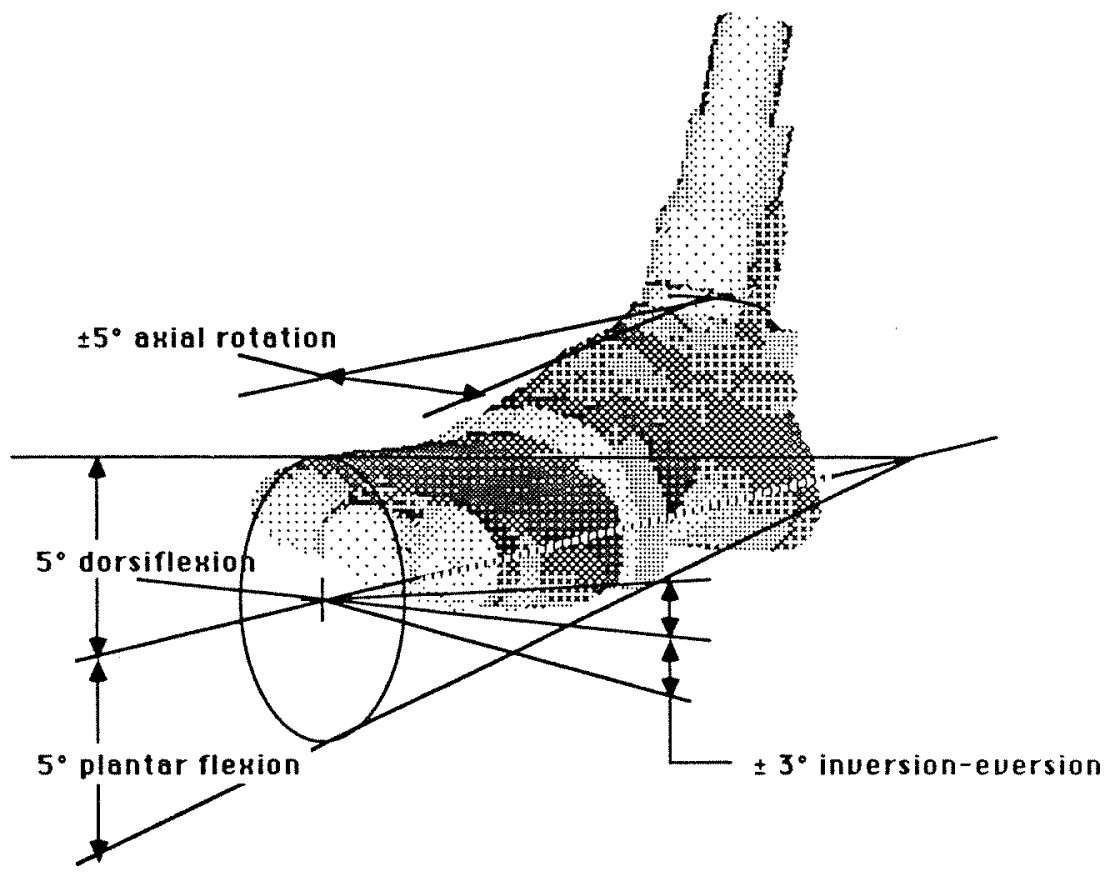

NOTE: Angular deflection defined by width of convoluted slit and mat'l properties. Values shown for 025 slit, flex $\bmod =500 \mathrm{k}$ psi.

\begin{tabular}{|c|c|c|c|}
\hline TITLE SEATTLE Ankle Funct & : sketch & $\begin{array}{l}\mathrm{PR} \\
\mathrm{RE}\end{array}$ & $\begin{array}{l}\text { HETICS } \\
\text { RCH }\end{array}$ \\
\hline NOTES: & $\begin{array}{l}\text { DRAWNBY: } \\
\text { Aulie } 3 / 23 / 87\end{array}$ & STU & 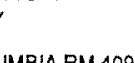 \\
\hline Ret. 1. Seattle ankle sketch & APPR'D BY: & $\begin{array}{l}1102 \mathrm{C} \\
\text { SEAT } \\
(206) \mathrm{E}\end{array}$ & $\begin{array}{l}\text { WA } 98104 \\
7717\end{array}$ \\
\hline c. Comvolutions, ankite & $\begin{array}{l}\text { PAOPRIETARY-DC } \\
\text { WTHOUT WRITE }\end{array}$ & $\begin{array}{l}\text { CATE } \\
\text { ATION }\end{array}$ & REV. \\
\hline
\end{tabular}

Figure 2.

SEATTLE Ankle function sketch. surfaces, fasteners, and their associated stress concentrations. The simplicity of this design and its ease of manufacture should result in low start-up costs and in being readily commercially available.

\section{DESCRIPTION}

\section{Function}

The VA/SEATTLE Ankle (Figure 1) is a lightweight monolithic design weighing approximately $300 \mathrm{~g}(10.5 \mathrm{oz}$.) with a maximum pylon length of $151 / 2$ in. (Actual weight depends on final length of pylon custom-cut per patient.)
Energy storage and release and three-axis motion (Figure 2) are accomplished via a specifically designed convolution (Figure 3) in a distal region (ankle) of the pylon. The convolution in the ankle provides rotation ( \pm 5 degrees), inversion/eversion ( \pm 3 degrees), and dorsi/plantar flexion ( \pm 5 degrees). The flexion/extension of the SEATTLE Foot (and other functionally similar feet) is enhanced when used in conjunction with this ankle.

The ankle functions as follows: 5 degrees plantar flexion allowed at heel strike; \pm 5 degrees elastically resisted axial rotation allowed until mid-stance; dorsiflexion blocking at 5 degrees flexion; and, \pm 3 degrees inversion/ eversion resisted at a rate of $15 \mathrm{ft}$. per pound. This limited 


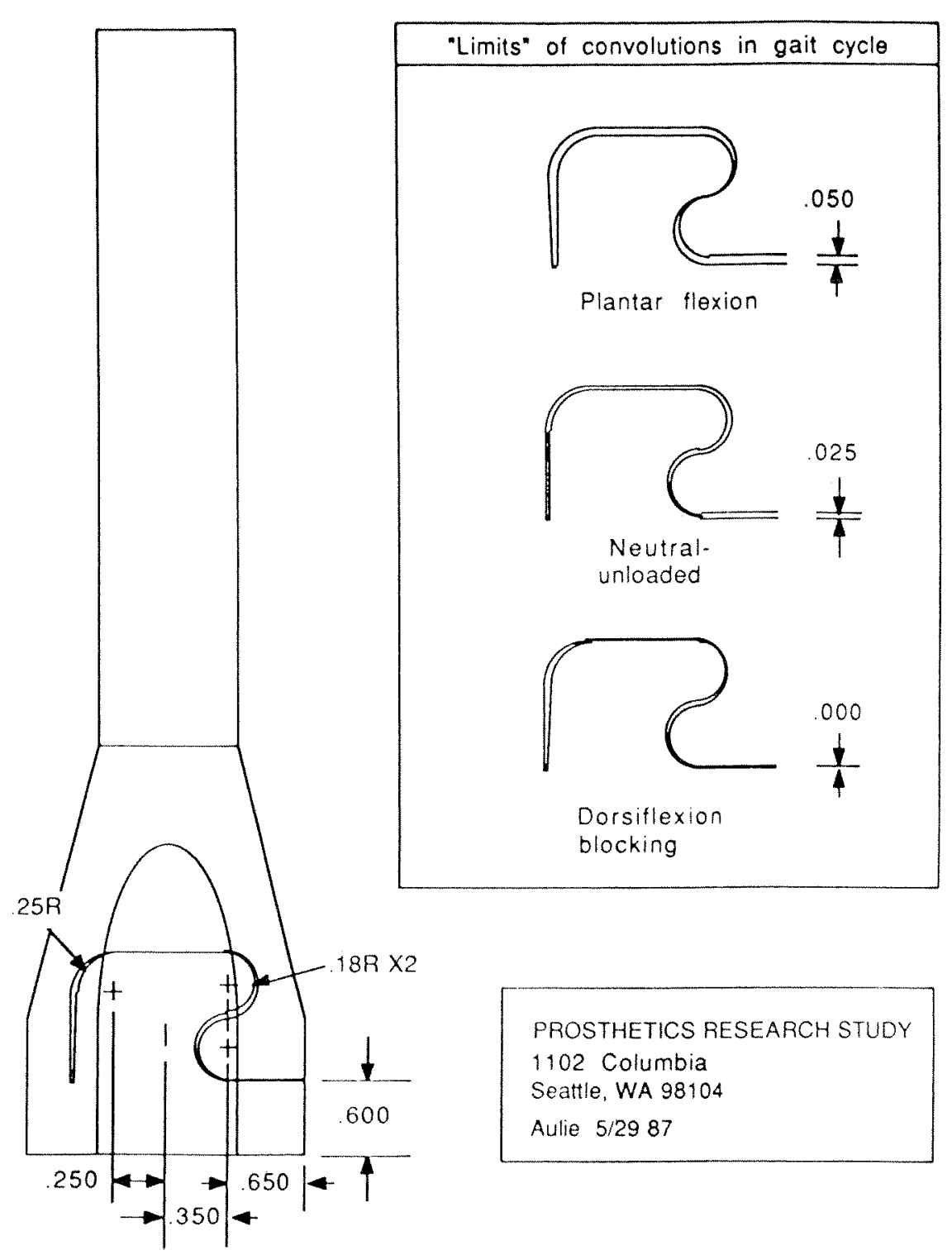

Figure 3.

"Limits" of convolutions in gait analysis. action provides a range of movement relevant to daily use while providing excellent stability-a very important feature to the geriatric amputee. Note that very rigid dorsiflexion blocking is necessary to operate the SEATTLE Foot and other similar designs.

\section{Installation}

Figure 4 illustrates the fitting of the VA/SEATTLE Ankle. The prosthetist was instructed not to sand, cut, glue, or paint the ankle but that marking with pencil or felt-tip pen was acceptable. The following installation features were evaluated:

\section{Compatibility with Other Components}

Pylons. The VA/SEATTLE Ankle can be interchanged as a substitute for $30 \mathrm{~mm}$ pylons from Otto Bock and Teh Lin. Other pylon diameters from USMC, Hanger, etc., which have adapters for $30 \mathrm{~mm}$ pylons, can also be used.

Feet. The ankle can be used with any type of $\mathrm{SACH}$ Foot with a single bolt attachment. Examples are SEATTLE Foot, Carbon Copy Foot, STEN Foot, SAFE Foot, and all standard and light SACH Feet. It should not be used with Symes, Single-Axis, or Multi-Axis Feet.

2. Length of Pylon

The VA/SEATTLE Ankle should be cut to a length to directly replace the existing endoskeletal SACH Foot 
FIGURE 4

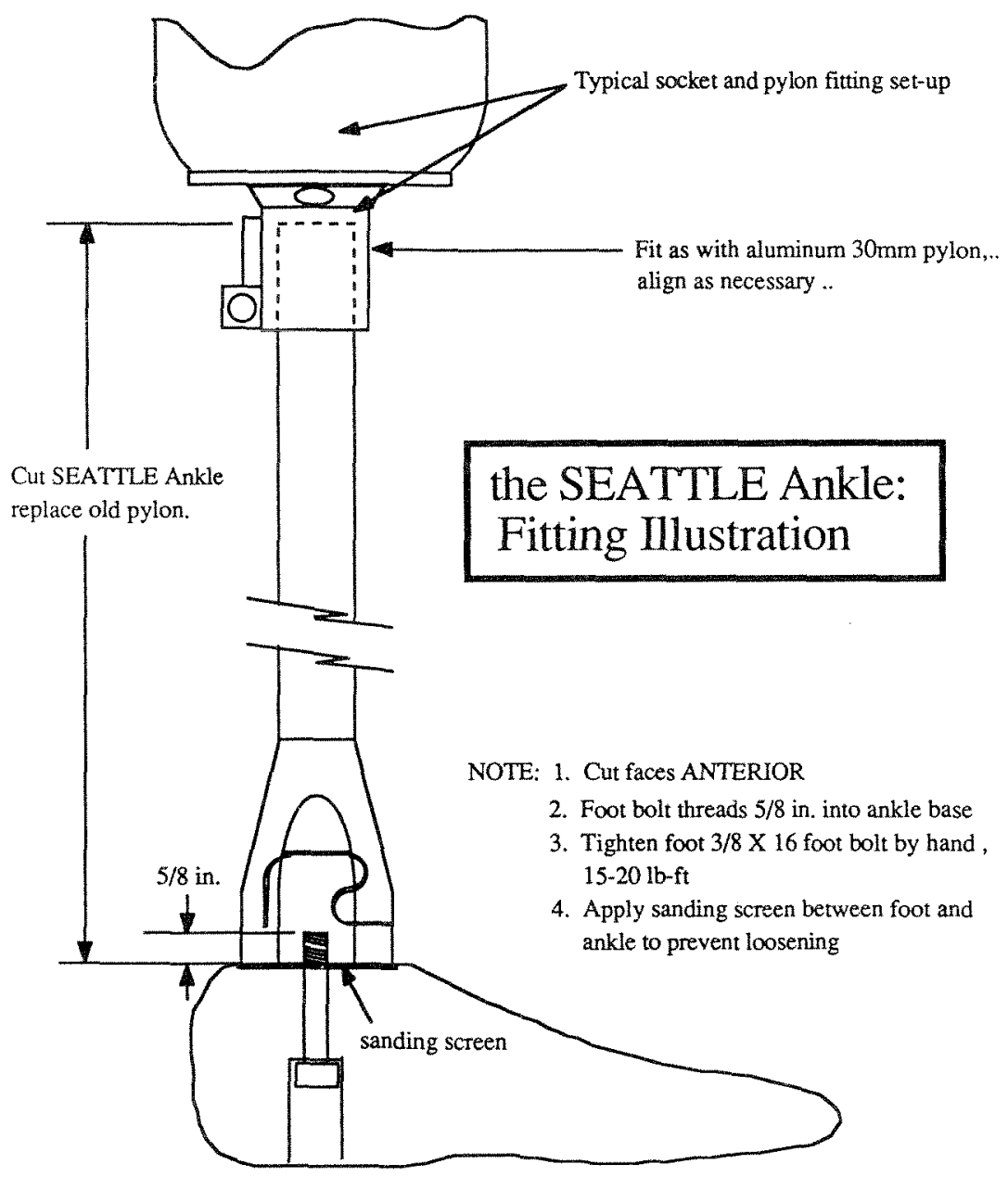

Figure 4.

The SEATTLE Ankle: fitting illustration. adaptor and pylon. The minimum length required for fitting the ankle is $51 / 2$ inches measured from the top of the foot to top of the ankle.

\section{Cosmetic Cover}

Any existing cosmetic foam cover not need to be modified to fit over the ankle. It may be necessary, however, to enlarge the distal opening of the cosmetic cover to accommodate the distal 2 inches of the ankle.

\section{Bolt Applications}

The foot is attached to the VA/SEATTLE Ankle according to the foot manufacturer's instructions. The prosthetist was instructed to: use the existing foot bolt only if it is 3/8-16 standard thread (the bolt should protrude a minimum of $1 / 2$ inch and a maximum of 1 inch from above the top of the foot); apply $12 \mathrm{ft}$. lbs. of torque to the bolt when installing the ankle; and, use the sanding screen supplied as a washer between the foot and the ankle to prevent rotation.

\section{Alignment}

The VA/SEATTLE Ankle can only be used where the pylon is aligned 90 degrees vertical to the top of the foot at midstance. This applies to both existing and newly fabricated prostheses. For new fabrication, the prosthesis should be aligned first with a temporary prosthetic alignment jig and then transferred to a VA/SEATTLE Ankle in vertical alignment.

\section{CLINICAL EVALUATION METHODOLOGY}

\section{General}

One hundred and twenty preproduction models of the VA/SEATTLE Ankle were purchased from PRS for a VA nationwide evaluation. Letters from regional directors to 18 VAMC directors initiated the clinical evaluation. This letter was accompanied by a procedures document and 
Journal of Rehabilitation Research and Development Vol. 28 No. 2 Spring 1991

evaluation questionnaires. The SEATTLE Ankles were furnished without cost to the participating VA medical centers by REU.

\section{Subject Selection}

Candidates screened could have had either above or below knee temporary limbs. The age of the candidate or activity level was not to be used as a basis for selection. The prime selection criterion was that the candidate had some experience in using a conventional type of pylon without ankle motion.

\section{Evaluation Sites}

VA Orthotic Laboratories. Eight VA Orthotic Laboratories were selected for fitting the SEATTLE Ankle on the temporary limbs they normally fabricate. Each facility received six units. The facilities were VAMCs in Decatur, GA, Dallas, TX, Hines, IL, Long Beach, CA, Memphis, TN, Minneapolis, MN, San Antonio, TX, and West Los Angeles, CA.

Commercial Facilities. Ten VA facilities were selected to conduct the clinical evaluation utilizing commercial prosthetic facilities currently having VA contracts. Each facility received five ankles. The facilities were VAMCs in Bay Pines, FL, Boston, MA, Chicago, IL (Westside), Martinez, CA, Richmond, VA, St. Louis, MO, Salt Lake City, UT, Tampa, FL, Washington, DC, and Winston Salem, NC.

\section{Prosthetist Participation}

A "Class I Clinical Evaluation Fee" for 1 hour labor at the current contracted rate was authorized in addition to the contracted cost of the endoskeletal limb being ordered. No other additions or deletions were authorized. If it was decided to fit the SEATTLE Ankle to an existing endoskeletal limb, the transaction was considered as a repair. In addition to the "Class I Clinical Evaluation Fee" of one hour labor at the contracted rate, one hour labor also was authorized to cover the prosthetist's time in removing the existing pylon and replacing it with a SEATTLE Ankle.

\section{Clinical Reports}

Reporting requirements involved an initial fitting report by the prosthetist and a follow-up report by the prosthetist and subject after the device had been worn for 30 days (see Appendices). Longer term reports were desirable but were voluntary. However, it was important to report any failures no matter when they occurred.

\section{Laboratory Tests}

The REU determined that cyclic laboratory tests to document durability and reliability over long-term use was necessary. The VA Prosthetics Assessment and Information Center (PAIC), Baltimore, MD, accomplished cycling tests on the ankle connected to a conventional SACH Foot under load. The cycle consisted of heel compression, midstance, and toe-break under an average load of $123 \mathrm{lbs}$.

\section{RESULTS}

\section{Laboratory Testing}

The laboratory tests conducted by PRS on the development models ( 11 design iterations and 60 prototypes) indicated a load-bearing capacity up to $2.5 \times$ body weight using a $200 \mathrm{lb}$. load as standard.

The PAIC's test procedures consisted of 500,000 cycles of the ankle attached to a conventional type SACH Foot under a dynamic load approximating the weight of a 150-170 lb. person. The ankle showed no signs of fracture or wear throughout the entire test procedure.

\section{Clinical Findings}

Fifty-three subjects were fitted through the Prosthetic and Sensory Aids Services at 13 VA Medical Centers. REU collected and analyzed the data resulting in the information below. Although 100 ankles were delivered to VAMCs for testing, it was decided to conclude the evaluation at the end of 53 reported cases. This decision was prompted by the extremely small variation-standard error-of reported data. REU continued to receive data on the remaining ankles with the expectation that the data variability would remain constant.

\section{Distribution of Subject(s) Per Field Station}

The number of subject fittings does not reflect the original distribution of five or six ankles per VAMC (see Table 1).The number reflects the availability of subjects. Ankles were moved from center to center as subjects became available.

Subjects included in the evaluation represented a broad range in age, weight, and activity level. The imbalance in sex reflects the normal veteran population. The heaviest subject ( $243 \mathrm{lbs}$.) did not report his activity level. Tables 2-7 provide breakdowns on subject characteristics.

Subject Response After Using the Ankle for a Minimum of 30 Days

The most active subjects averaged 51 years in age and 
Table 1. Geographical distribution

\begin{tabular}{|c|c|c|}
\hline VAMC & & Subjects fitted \\
\hline Chicago, IL (Westside) & & 3 \\
\hline Dallas, TX & & 5 \\
\hline Decatur, GA & & 4 \\
\hline Hines, IL & & 3 \\
\hline Los Angeles, CA (West) & & 11 \\
\hline Martinez, $\mathrm{CA}$ & & 6 \\
\hline Memphis, TN & & 6 \\
\hline Minneapolis, MN & & 2 \\
\hline Richmond, VA & & 1 \\
\hline St. Louis, MO & & 1 \\
\hline Salt Lake City, UT & & 5 \\
\hline San Juan, PR & & 5 \\
\hline \multirow[t]{2}{*}{ Winston-Salem, NC } & & 1 \\
\hline & Total & 53 \\
\hline
\end{tabular}

Table 2

\begin{tabular}{lr}
\hline \multicolumn{1}{c}{ Sex } \\
\hline Male & $92 \%$ \\
Female & $8 \%$ \\
Total & $100 \%$ \\
\hline
\end{tabular}

Table 3.

\begin{tabular}{cc} 
& Age distribution \\
\hline $23-30$ & $4 \%$ \\
$31-40$ & $19 \%$ \\
$41-50$ & $17 \%$ \\
$51-60$ & $17 \%$ \\
$61-69$ & $19 \%$ \\
$70+$ & $11 \%$ \\
Unknown & $13 \%$ \\
Total & $100 \%$ \\
\hline
\end{tabular}

Table 4.

\begin{tabular}{cc} 
Weight range \\
\hline $0-150(\mathrm{lb})$ & $17 \%$ \\
$151-199$ & $62 \%$ \\
$200+$ & $19 \%$ \\
Unknown & $2 \%$ \\
(heaviest $=243 / \mathrm{lbs})$. & \\
Total & $100 \%$ \\
\hline
\end{tabular}

ranged in weight from 170 to 227 lbs. They were likely to wear an energy storing/release foot and considered the SEATTLE Ankle an asset. This group in general would accept increased performance of the ankle motion, especially eversion and rotation.

The medium activity group averaged 49 years in age and ranged in weight from 131 to 230 lbs. They had less than 50 percent chance being a wearer of an energy storing/ release foot, but also considered the SEATTLE Ankle an asset. The anomaly concerning a slightly lower average age group having medium activity was not considered significant. The salient feature was the use of an energy storing/release foot.

The lowest activity group were older, averaging 63 years and they ranged in weight from 140 to $235 \mathrm{lbs}$. They did not use an energy storing/release foot but considered the ankle adequate and generally helpful to them.

Table 7 shows the assessment of the three groups of subjects. Appendix $\mathbf{C}$ represents the form used by subjects in evaluating the ankle after 30 days of use.

The subjects' responses when asked to rate their performance during certain activities with the SEATTLE Ankle as compared to what they previously used is summarized in Table $\mathbf{8}$. The average response was calculated

Table 5.

\begin{tabular}{lr}
\multicolumn{2}{c}{ General activity level* } \\
\hline High & $36 \%$ \\
Medium & $38 \%$ \\
Low & $25 \%$ \\
Unknown & $1 \%$ \\
Total & $100 \%$
\end{tabular}

* General activity level is an indicator on how much and what type of activities the subject does.

High: frequent walking and ambulatory activities; active in (ambulatory) sports.

Medium: moderate amount of walking and ambulatory activities; some (ambulatory) sports.

Low: minimal amount of walking and ambulatory activities; no (ambulatory) sports

Table 6.

\begin{tabular}{lrr} 
& Amputation level \\
\hline Below-knee & $87 \%$ \\
Above-knee & $11 \%$ \\
Unknown & $2 \%$ \\
Total & $100 \%$
\end{tabular}


Journal of Rehabilitation Research and Development Vol. 28 No. 2 Spring 1991

for the subjects as a whole and then by activity level groups. Improved performance in all ambulatory functions is explicitly shown in the ratings given by the subjects for walking either slow or fast (7.5 for slow, 7.3 for fast), running (6.0), going up stairs (7.3) or down stairs (7.4), going up hills (7.1) or down hills (6.9), and going over uneven terrain (7.5). The group of subjects with the highest activity level showed an even greater improvement rating. Table 8 shows that: (1) moderate improvement was achieved in running; (2) high activity persons detected downhill improvement; and, (3) high activity subjects consistently improved.

Table 9 presents the subjects' rating of the degree of rotation provided by the ankle.

\section{Prosthetist Interpretation}

The prosthetists reported that fittings went comparatively easily except in six instances were the pylon diameter did not directly fit the alignment jig or knee receptor. The form used by the prosthetists for fitting evaluation is presented in Appendix A. Prosthetists' comments and interpretation of subjects' feedback after a minimum of 30 days use by the subject is shown in Table 10. Data are summarized by percentages within groupings of the subjects' response when questioned on degree of specific ankle function. A prosthetist form for 30-day follow-up subject evaluation is presented in Appendix $\mathbf{B}$.

Ninety-eight percent of the subjects reported that ankle movement was smooth during all phases of gait. The functioning of the ankle was essentially noiseless and failure free. Only three subjects reported functional failures during the evaluation period. These failures were caused by: (1) a bolt broken while playing golf; (2) a helicoil pulled out during running; and, (3) a bolt broken while walking on uneven terrain.

\section{Comments by Subjects and Prosthetists}

A large percentage of subjects indicated that the defined motion of the SEATTLE Ankle as tested was acceptable. Results on two functions require addressing: (1) the degrees of plantar flexion, and (2) rotation. The subjects in the highest activity group preferred more plantar flexion, while those in the medium and low activity groups desired it to stay as was. Secondly, 53 percent of the subjects wanted to keep the amount of rotation as it was, while 23 percent wanted more rotation. In opposition to this result is the

Table 7. Qualitative assessment of the ankle by activity level, age, and type of foot

\begin{tabular}{lcccc}
$\begin{array}{c}\text { General } \\
\text { activity } \\
\text { level }\end{array}$ & $\begin{array}{c}\text { No. of } \\
\text { subjects }\end{array}$ & Average & Using SEATTLE & $\begin{array}{c}\text { Used } \\
\text { Ankle an } \\
\text { amprovement }\end{array}$ \\
\hline ighecial & 19 & 51 & $73 \%$ & $65 \%$ \\
foot
\end{tabular}

NOTE: Special foot means one that stores and releases energy during use (e.g., the SEATTLE Foot).

Table 8. Performance level by activity function

\begin{tabular}{|c|c|c|c|c|c|c|c|c|}
\hline $\begin{array}{c}\text { General } \\
\text { activity } \\
\text { level }\end{array}$ & $\begin{array}{l}\text { Walk } \\
\text { slow }\end{array}$ & $\begin{array}{l}\text { Walk } \\
\text { fast }\end{array}$ & Run & $\begin{array}{c}\text { Go } \\
\text { upst. }\end{array}$ & $\begin{array}{c}\text { Go } \\
\text { dwnst. }\end{array}$ & $\begin{array}{c}\text { Up } \\
\text { hill }\end{array}$ & $\begin{array}{c}\text { Down } \\
\text { hill }\end{array}$ & $\begin{array}{l}\text { Uneven } \\
\text { terrain }\end{array}$ \\
\hline $\begin{array}{l}\text { All } \\
\text { subjects }\end{array}$ & 7.5 & 7.3 & 6.0 & 7.3 & 7.4 & 7.1 & 6.9 & 7.5 \\
\hline High & 7.9 & 6.3 & 6.5 & 7.7 & 7.8 & 7.9 & 8.0 & 7.6 \\
\hline Medium & 7.8 & 7.6 & 6.1 & 7.3 & 7.3 & 7.0 & 6.2 & 7.4 \\
\hline Low & 7.0 & 6.8 & 5.6 & 6.8 & 6.9 & 6.3 & 6.4 & 6.8 \\
\hline
\end{tabular}

Rating Scale: 1 (worse than) . 5.5. (equal to) . . 10 (easier than) 
prosthetist interpretation of the subjects' requirements, which indicated that 55 percent wanted more, while 45 percent wanted to keep it as was.

The comments from the prosthetists to broaden the compatibility of the SEATTLE Ankle to mate well with existing alignment jigs and prosthetic knee units were reviewed by the PRS development team and the prospective manufacturer. Prosthetists' suggestions for improvements were primarily concerned with mating the ankle's pylon to a broader variety of knee receptors and belowknee alignment jigs (e.g., the Berkeley Alignment Jib and the Hosmer Ultra Roelite Modular Knee).

\section{CONCLUSION}

The VA/SEATTLE Ankle unit seemed to have met the design goal of being a replacement for most belowknee and above-knee endoskeletal pylons. The experiences of persons with lower limb amputations who used the SEATTLE Ankle throughout this evaluation endorsed the success of the project goal for improving gait. Selected comments by subject users follow.

"Yes, I'm walking better and have more spring action using the SEATTLE Ankle."

"I prefer the SEATTLE Ankle, it allows easier walking and is more flexible than my previous prosthesis."

"Yes, the SEATTLE ankle is much lighter and restores some lost ankle movements."

Common descriptor used by subjects evaluating the VA/SEATTLE Ankle include "more natural gait," " better traction," "flexibility," "lightweight," "improved gait," "more stability," "more bounce or spring to my step," "feels more natural and is easier to walk with."

This evaluation determined that the performance of the VA/SEATTLE Ankle proved to be acceptable and reliable with a wide variety of users and its commercial production was recommended.

Table 9. Percentage* of subjects reporting on ankle rotation

\section{General}

activity level

Just right

Too stiff

Too loose

Unknown

All

Subjects

High activity

Medium activity

Low activity

53.0
20.0
15.0
18.5

23.0

9.5

9.5

5.0

* Percentage of respondents within each group.

Table 10. Prosthetist interpretation of Ss desire for ankle function in percent

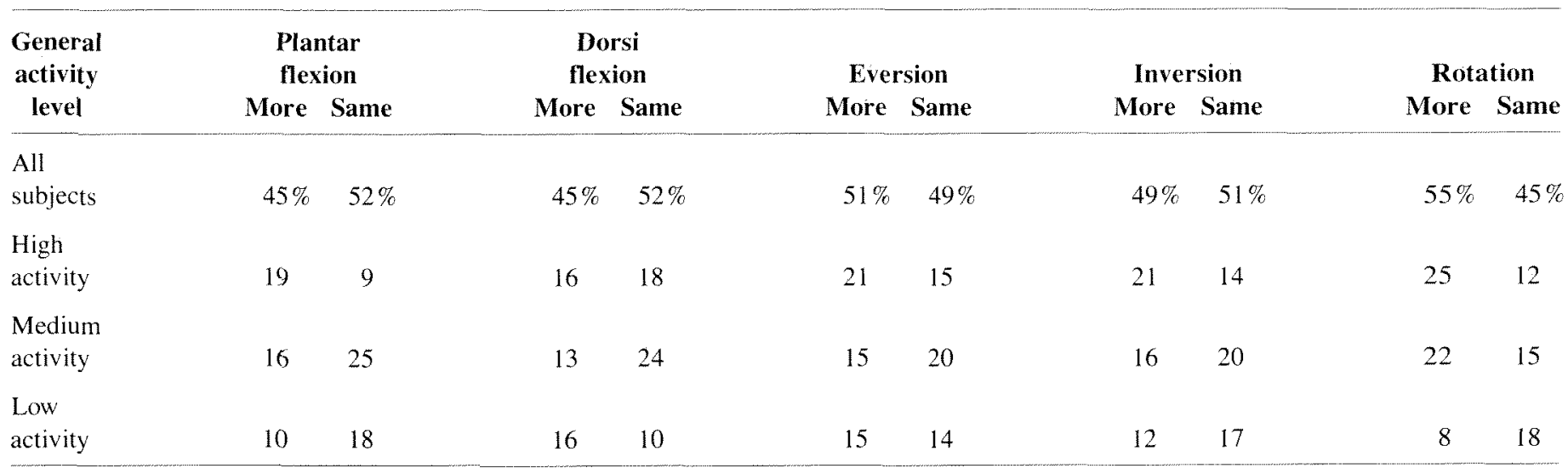




\section{APPENDIX A \\ Prosthetist's Evaluation: Fitting}

TO: Director, VA Rehab R\&D Evaluation Unit

Prosthetics R\&D Center

103 So. Gay Street

Baltimore, MD 21202

FROM: CHIEF, PROSTHETIC SERVICE, VAMC

SUBJ: Prosthetist's Evaluation - Seattle Ankle Fitting

Veteran's Name

Birthdate

Amputation Side

Weight

Activities

Sex Level SC Nength of Stump Overall

Activity Level (Low, Medium, High)

Prosthesis Description

Foot Type Foot Size Shoe Size
Part Number

Cut Length Overall

3/8" Bolt Length

\section{Weight}

Weight

Prosthetist

Prosthetist's comments on fitting

Prosthetist's comments on function: (plantar-dorsiflexion, inversion, eversion, rotation)

Prosthetist's interpretation of Subject impressions of function

Notes* Each ankle has undergone bench testing to assure its safety. Should failure occur for any reason, call the Prosthetics Research Study (206) 622-7717 and return the part to VA Rehab R\&D Evaluation Unit, Prosthetic R\&D Center, 103 South Gay Street, Baltimore, MD 21202 


\section{APPENDIX B \\ Prosthetist's Evaluation: 30 Day Follow-Up}

TO: Director, VA Rehab R\&D Evaluation Unit

Prosthetics R\&D Center

103 South Gay Street

Baltimore, MD 21202

FROM: Chief, Prosthetic Service, VAMC

SUBJ: Prosthetist's Evaluation - Seattle Ankle 30-day Follow-up

Date

Part

Veteran's Name

Weight

Part Number

Prosthetist

Prosthetist's interpretation of Subject feedback

Would Subject like "more"/"less": Rotation .............

Inversion. . . . . . . . .

Eversion . . . . . . . . . . .

Plantarflexion............

Dorsiflexion ............

Is Ankle movement smooth during all phases of gait?

If no, explain

Has Ankle movement increased since fitting?

In what ways?

Noise?

When?

From where?

Failure?

Where?

When?

What was Subject doing?

Did the foot loosen from the Ankle?

What was used to affix the foot to the Ankle? (hot glue, sanding screen . . .)

Prosthetist's suggestions for improving Ankle design 


\section{APPENDIX C}

\section{Subject's Evaluation: 30-Day Follow-Up}

TO: Director, VA Rehab R\&D Evaluation Unit

Prosthetics R\&D Center

103 South Gay Street

Baltimore, MD 21202

FROM: Chief, Prosthetic Service, VAMC

SUBJ: Veteran Questionnaire - SEATTLE ANKLE - 30-day Follow-up

Veteran's Name

Date

Part

Have you used the Ankle on a daily basis?

Have you used the Ankle while participating in sports?

During what specific activities have you used this Ankle?

Please rate the difficulty to perform the following activities using your new Ankle as compared to the ankle that you wore previously ...

Walk slowly

Walk fast

Run

Go up hill

Go downhill

Go upstairs

Go downstairs

Uneven terrain

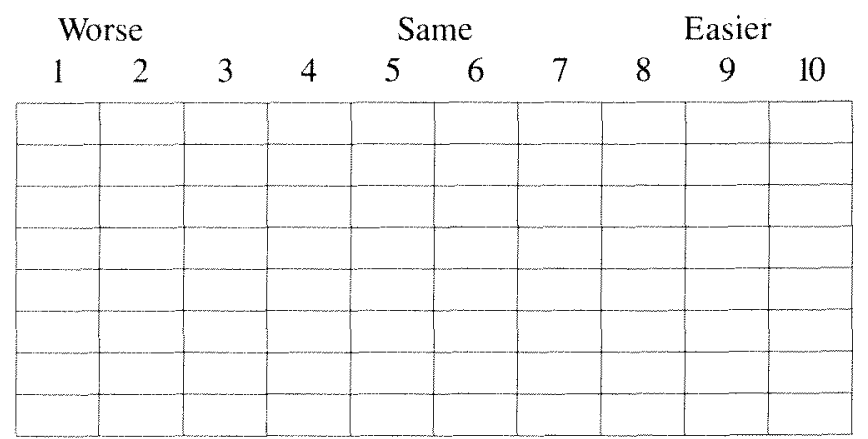

Are there any other specific activities where the function of the Ankle has been noticeable? Which?

How would you rate the degree of rotation (twist) provided by the Ankle . . [ ] Just Right [ ] Too Stiff [ ] Too Loose Do you have any other comments, suggestions, or criticisms with regard to this Ankle design that might help us improve it for other amputees?

Do you consider using the Ankle an overall improvement over using your prosthesis without the Ankle? Why? 